\title{
Decennial comparison of changes in social vulnerability: A municipal analysis in support of risk management
}

\author{
A.O. Tavares ${ }^{\mathrm{a}, *}$, J.L. Barros ${ }^{\mathrm{b}}$, J.M. Mendes ${ }^{\mathrm{c}}$, P.P. Santos ${ }^{\mathrm{d}}$, S. Pereira ${ }^{\mathrm{d}}$ \\ a Earth Sciences Department and Centre for Social Studies, Universidade de Coimbra, Rua Silvio Lima, Pólo II, 3030-790 Coimbra, Portugal \\ ${ }^{\mathrm{b}}$ Centre for Social Studies, Universidade de Coimbra, Colégio de S. Jerónimo, Apartado 3087, 3000-995 Coimbra, Portugal \\ ${ }^{\mathrm{c}}$ Faculty of Economics and Centre for Social Studies, Universidade de Coimbra, Colégio de S, Jerónimo, Apartado 3087, 3000-995 Coimbra, Portugal \\ ${ }^{\mathrm{d}}$ Centre of Geographical Studies, IGOT, Universidade de Lisboa, Rua Branca Edmée Marques, Cidade Universitária, 1600-276 Lisboa, Portugal
}

\section{A R T I C L E I N F O}

\section{Keywords:}

Social Vulnerability

Criticality

Support Capability

Municipal level

Risk management

\begin{abstract}
A B S T R A C T
The concept of Social Vulnerability (SV) is characterized and distinguished by its complexity and multidisciplinarity. This concept takes into account the specific characteristics of the individual and his social and economic relations, as well as the physical environment where he is inserted. These differentiating characteristics make Social Vulnerability (SV) an indispensable work tool in the process of characterizing and understanding the degree of exposure of communities, as well as evaluating their capacity for resilience and recovery from hazardous events.

This paper presents a comparison between the SV performed in 2008 with the results obtained in 2017 for the 278 municipalities of mainland Portugal. The methodology was based on the work developed by the Center for Social Studies of the University of Coimbra, which is distinguished by the fact that SV is composed of two components: Criticity and Support Capability. The analysis of SV and its components was done using Principal Components Analysis (PCA) starting from an initial set of 235 variables (90 for Criticality and 145 for Support Capability).

With respect to Criticality, the results point out the importance of factors related to the economic condition, employment and factors related to the disadvantaged population and risk groups. Support Capability is strongly influenced by the population density and the most relevant factors for the final results are those related to civil protection response, economic and environmental dynamism and logistic and service capacity. Regarding the SV spatial distribution, the highest values are located mainly in the central and northern parts of the country, with emphasis on the Douro river valley and surrounding municipalities; also a general decrease of SV was recorded in the southern regions from 2008 to 2017.
\end{abstract}

\section{Introduction}

There are multiple and distinct methods of measuring vulnerability [1-3]. The severity of impacts and the resilience to them are largely predicted by the cultural, institutional and social characteristics underlying the concept of vulnerability [4]. Vulnerability can be defined as the conditions determined by the physical, social, economic and environmental factors or processes that increase the susceptibility of a community to the impact of hazards [5].

The multi-faceted scope of the concept leads to the specific necessity of considering Social Vulnerability (SV) as a particular feature of vulnerability, and its measurement is also subject to distinct approaches [6-8]. SV is a multidimensional concept that allows us to characterize and understand the level of a given community's exposure to risks and to understand how it can respond and recover in post-disaster periods [9].

The concept of SV can then be characterized by its multidimensionality and complexity. It is related to the characteristics of the individual, but also his social and economic relations, as well as the physical and social environment where the individual is inserted [10]. The concept also involves a collective dimension, which considers the preexisting characteristics that influence the preparation, response and recovery from disasters [11]. These characteristics make SV an indispensable tool for the characterization and understanding of the degree of exposure of the communities, but also their capacity for resisting and recovering in face of hazardous events. The evaluation of SV as a tool

\footnotetext{
* Corresponding author.

E-mail addresses: atavares@ci.uc.pt (A.O. Tavares), leandrobarros@ces.uc.pt (J.L. Barros), jomendes@ces.uc.pt (J.M. Mendes), pmpsantos@campus.ul.pt (P.P. Santos), susana-pereira@campus.ul.pt (S. Pereira).
} 
for measuring risk management strategies has grown in recent decades and has been carried out in several contexts, for example, regarding the risk of floods [12], tsunami [13,14], environmental hazards [15] and climate change [16].

In Portugal SV was previously evaluated at the municipal level in order to better consider the interdependencies between environmental and societal structures [17]. Later, in the course of a research project coordinated by the Center for Social Studies of the University of Coimbra, a new methodological approach was introduced in which the SV assessment considers two dimensions - Criticality and Support Capability - using an inductive approach [18]. The concept of Criticality is understood as the set of characteristics and behaviors intrinsic to the individuals who may contribute to the disruption of the context where the individual is placed and the resources of the communities that allow them to deal with and respond to harmful events. Support Capability is understood as the set of territorial infrastructures that allows risk managers to react in case of disaster and could support the recovery. This conceptual development would better allow for the operationalization of the SV as a planning tool, supporting the implementation of a territorial model in which risk assessment and management would be more fully informed for decision making. Assessing the role of critical infrastructure in reducing vulnerability is essential for effective risk management policies. Not only the isolated function of such structures is to be considered as their interdependencies [19].

Having this context in mind, the mains objectives of the presented research are:

- Expression of the Social Vulnerability components in 2008;

- New analysis of the Social Vulnerability components in 2017;

- Comparision and discussion of the municipal Social Vulnerability evolution.

The present study focuses on the calculation of SV for the 278 municipalities of mainland Portugal (Fig. 1), with a total area of $89.089 \mathrm{~km}^{2}$ and a 2011 resident population of 10.044 .484 inhabitants [20]. In administrative terms Portugal is divided into three NUT's (Nomenclature of Territorial Units for Statistics) levels, defined according to population, administrative and geographical criteria, in accordance with Law-Decree 244/2002, changed in 2015 by Regulation $n^{\circ} 868 / 2014$. The present work is developed at the level of NUT III, which is composed of 23 territorial units, including 278 municipalities (Fig. 1).

With regard to socio-economic characterization, mainland of Portugal is characterized by a clear dichotomy between the coastal area, more densely populated, with a younger population, more industrialized and with greater economic dynamism, and the inland area, more rural and aged, less dynamic economically, where the territories of low density predominate. Fig. 1 presents three socio-economic variables (population density, percentage of employed population in the secondary sector, which includes manufacturing industry and construction, and percentage of purchasing power), which help to understand the national continental territory. As far as population density (Fig. 1a) is concerned, the highest values are located in coastal areas and in biggest cities and surrounding areas, as well as in district capitals. Regarding the sectors of activity, mainland Portugal also presents a clear dichotomy between the more industrialized coastline and the inland area where the tertiary sector and the areas related to the agricultural and forestry sector are most marked. The analysis of the output referring to the percentage of population employed in the secondary sector (Fig. 1b), shows that the highest values are concentrated in the northern and central coastal zone, with emphasis on the areas bordering the Metropolitan area of Oporto, central region, with emphasis on the industry linked to the automotive sector, wool and dairy products. Also noteworthy are the importance of the port of Sines and the mining complex of Aljustrel that stand out in the southern part of
Portugal, more precisely in the Alentejo. In terms of quality and living conditions, the percentage of purchasing power (Fig. 1c) allows us to observe a higher purchasing power per capita in the coastal and south zone compared to the more inland areas. There is also a clear contrast between the innermost regions of the north, which have a lower purchasing power compared to the rest of the continental territory.

\section{Methodology}

\subsection{Statistical procedures}

The SV is assessed using PCA methodology advocated by Cutter et al. [15], Schmidtlein et al. [21], Mendes [17], Chen et al. [11], Guillard-Gonçalves et al. [22], de Loyola Hummell et al. [23] and Tavares et al. [24], with some adaptations made according to regional and local social and geographical specificities. For the PCA, SPSS ${ }^{\circledR}$ software, version 23 was used. The data that supports this evaluation were obtained from the 2011 Census [20] and PORDATA database [25]. The period of the data used varies between 2011 and 2016.

The Redundancy Analysis (RDA) is a multivariate, direct gradient analysis method in which individuals are presumed to have linear relationships to environmental gradients (i.e. linear species response curves), and it was conducted using the $\mathrm{Canoco}^{\circledR}$ software, version 5. This software is designed for multivariate statistical analysis using ordination methods in the field of ecology and several related fields [26]. As with the 2008 SV assessment, the 2017 updated analysis considered the components of Criticality and Support Capability introduced in Mendes et al. [18] as mention above.

Prior to the final running of PCA, redundant variables are eliminated (the same procedure was carried out in the 2008 analysis) based on the iterative and combined analysis of several indicators: Pearson correlation matrix; variance rate parameters, which should be greater than 60\%; Kaiser-Meyer-Olkin (KMO) sample measurement, which should be greater than 0.6 [27]. After the definition of the final set of variables, PCA is carried out using normalized values to the z-score, Varimax rotation factor analysis. An analysis of the cardinality or sign interpretation of each principal component is done - identifying in the rotated matrix the variables that have a loading equal to or greater than the module of 0.5 - so the factors may be interpreted and, if needed, their respective scores multiplied by $-1[15,18]$. This is justified by the fact that PCA cannot interpret the role of variables in increasing or decressing vulnerability. For example, a high $\%$ of persons with higher education may present a positive loading, thus requiring an inversion of scores so that a high \% in that variable contributes to lower criticality.

After calculating Criticality and Support Capability, the Social Vulnerability composite index is calculated by combining the two components mentioned above. The calculation is made using the following equation:

Social Vulnerability $=$ Criticality $\times(1-$ Support Capability $)$

The Eq. (1) is designed so that high values of Criticality and low values of Support Capability would represent a worse or higher Social Vulnerability composite index.

The results obtained are grouped into different classes that vary from very low to very high in accordance with the standard deviation (SD) and the following categories: "very low," < $1 \mathrm{SD}$; "low," [ -1 , $-0.5 \mathrm{SD}]$; "moderate," [- 0.5, + 0.5 SD]; "high," [0.5, $1 \mathrm{SD}]$; "very high," $\geq 1$ SD [15].

\subsection{Criticality, Support Capibility and Social Vulnerability in 2008}

As mentioned before, the 2008 assessment of SV was conducted in the course of a research project coordinated by the Center for Social Studies of the University of Coimbra [18] and was based on principal component analysis (PCA) resulting in a total of 32 variables representative of 9 SV dimensions (Table 1). PCA was applied both to 


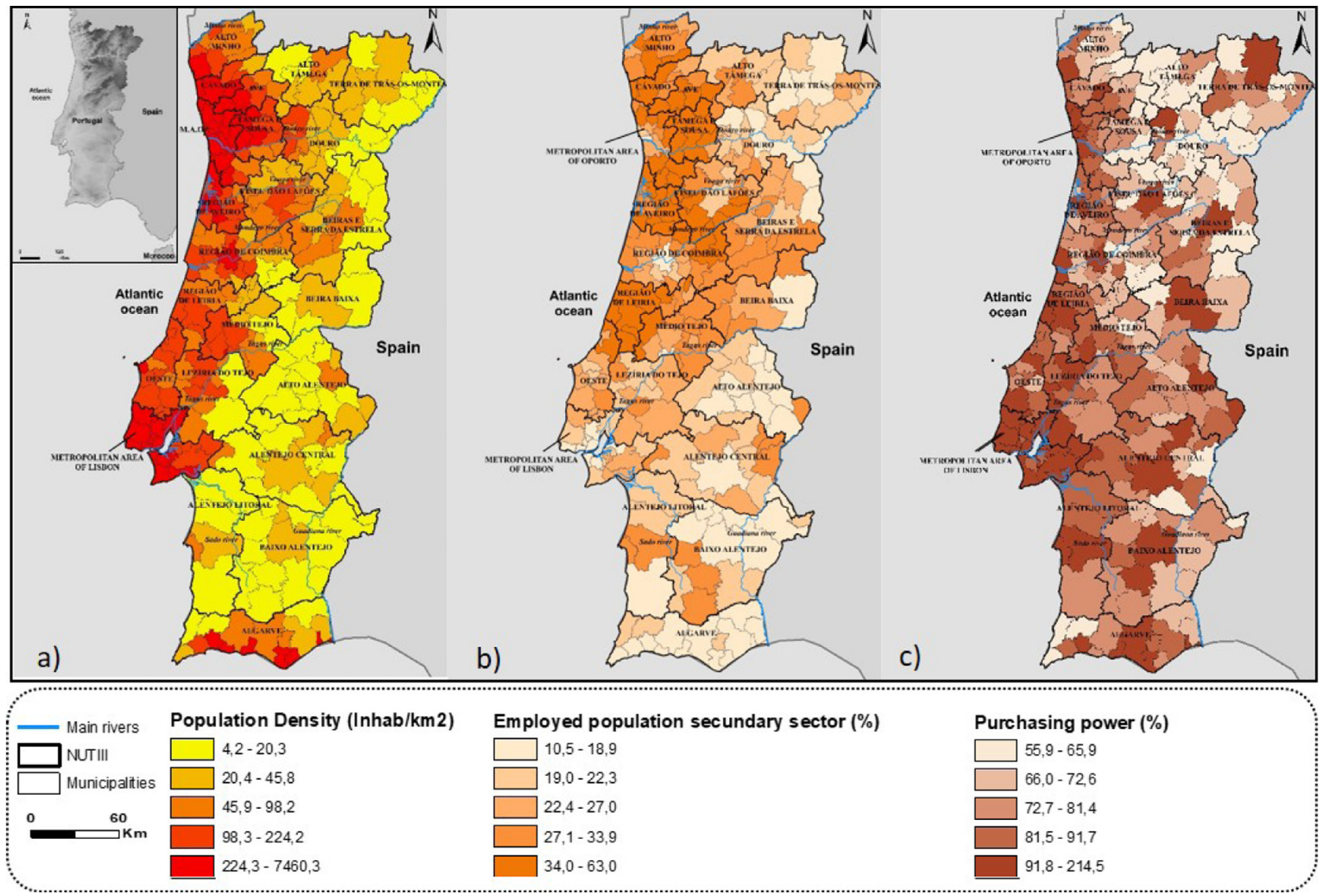

Fig. 1. Population density (a), employed population in secondary sector (b) and purchasing power (c) at the municipal level in 2017.

Table 1

SV dimensions and number of explanatory variables used in the calculation of Criticality and Support Capability in the 2008 assessment.

\begin{tabular}{lll}
\hline SV dimensions & $\begin{array}{l}\text { Variables used in } \\
\text { Criticality }\end{array}$ & $\begin{array}{l}\text { Variables used in Support } \\
\text { Capability }\end{array}$ \\
\hline $\begin{array}{l}\text { Social support } \\
\text { Housing conditions }\end{array}$ & 2 & \\
Demography & 2 & \\
Economy & 9 & 4 \\
Education & 2 & \\
Housing & 4 & 1 \\
Health & & \\
Civil protection & & 2 \\
Health & & 3 \\
\hline
\end{tabular}

components of Criticality and Support Capability.

For the evaluation of the Criticality, 90 variables were used in the first approach, which were reduced to 56 after a multicollinearity analysis from the bivariate correlations between them. The application of PCA allowed the selection of 22 explanatory variables (Table 1 ). Based on the 22 explanatory variables of Criticality, a total of 6 factor analysis components (FAC's) were retained for analysis with a variance rate of $76 \%$ and a KMO of 0.756 and all communalities above 0.6 . In terms of Support Capability, 145 variables were first considered, which were reduced to 61 after a multicollinearity analysis from the bivariate correlations between them. The application of the factor analysis allowed the selection of 10 explanatory variables (Table 1). Based on the 10 explanatory variables of Support Capability, a total of 4 FAC's were retained for analysis with a variance rate of $71 \%$ and KMO of 0.700 and all communalities above 0.6 .

\subsection{Criticality in 2017}

The current calculation of the Criticality index for the municipalities of mainland Portugal was carried out using 22 variables (Table 2), which try to replicate the same set of explanatory variables (i.e., those self-grouped around the principal components and whose module of the loading was higher than 0.5) used in the 2008 assessment [18]. The 22 variables are grouped into seven groups, representing distinct dimensions or forcers of Criticality: social support, demography, housing conditions, economy, education, housing and health.

Whenever possible, the same variables used in 2008 were also used in the 2017 assessment. However, for different reasons, namely the lack of updating of some variables and the discontinuation of others, it became necessary to carry out a research work in order to find new variables that currently represent as closely as possible the reality represented by those variables used in 2008 (variables in bold in Table 2). Thus, a total of 10 new variables were introduced (in bold in Table 2) in comparison to the set used in 2008.

Based on the 22 variables presented in Table 2, 6 factors (FAC's) were retained for analysis. These factors present a variance rate of $73 \%$ for the 278 municipalities under study, with a KMO of 0.726 and all communalities above 0.6 .

\subsection{Support Capability in 2017}

The calculation of the Support Capability index at the municipal level was performed using 12 variables (Table 3), based on the 
Table 2

Variables used in the 2017 Criticality assessment.

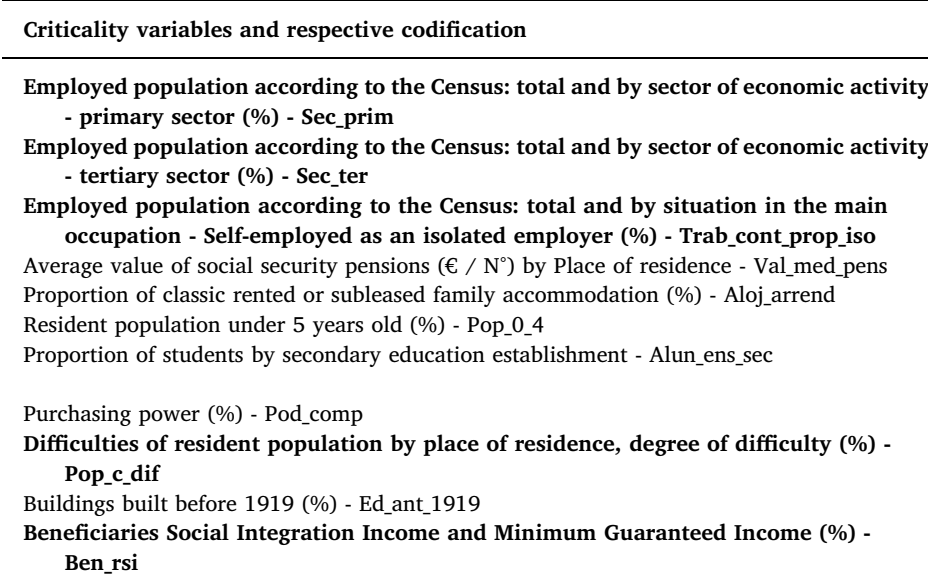

Employed population according to the Census: total and by sector of economic activity - secondary sector (\%) - Sec_secun

Employed population according to the Census: total and by situation in the main occupation - self-employed as an employer (\%) - Trab_cont_prop Employed population according to the Census: total and by situation in the main profession -Worker on behalf of others (\%) - Trab_cont_outr

Proportion of students by pre-school education establishment - Alun_pre_esc Resident population older than 65 years (\%) - Pop_ > 65

Seasonal households (\%) - Aloj_saz

Deposits from customers in banks, savings banks and mutual agricultural credit: total and by type of customer / hab - Dep_clie

Social housing - social and supported renting (\%) - Aloj_ren_soc

Very degraded buildings (\%)

Housing with renting less than 100 euros (\%) - Aloj_r $<100$

Notarial acts entered into by writ - Properties buying and selling (\%)
Table 3

Variables used in Support Capability assessment.

\begin{tabular}{l}
\hline Support Capability variables and respective codification \\
\hline ATM machines (\%0) - MB_1000 \\
Urban waste collected - kg/hab - Res_urb \\
Banks and savings banks (\%0) - Ban_caix \\
Accommodation capacity in hotel establishments /1000 hab - Cap_aloj \\
Firefighting corporations (\%0) - Corp_Bomb \\
Firefighters/1000 hab - Bomb_1000 \\
Proportion of collective accommodation - Aloj_colec_per \\
Proportion of hospitals per 10,000 inhabitants - Hosp_10000 \\
Insurance companies (\%) - Com_segur \\
Pharmacies per 10,000 inhabitants Farm_10000 \\
Inhabitants by covered spaces - Hab_esp_cob \\
Road network density - Rv_dens
\end{tabular}

explanatory variables (10 variables) that resulted from the factorial analysis carried out in 2008 [18]. The variables are grouped into four distinct groups: economy; building characteristics; civil protection resources and health facilities. As previously mentioned for the Criticality assessment, the same 2008 assessment variables were used whenever possible (with temporal updating). The variables that appear in bold in Table 3 represent the new variables introduced, with an emphasis on the variables "inhabitants by covered spaces" and "road network density".

Based on the 12 variables presented in Table 2, a total of 3 FAC's were retained for analysis. These factors present a variance rate of $65 \%$ for the 278 municipalities under study, with a KMO of 0.705 and all communalities above 0.6 .

\section{Results for 2017}

\subsection{Criticality at municipal level}

The Criticality assessment allowed us to identify 6 factors that resulted from PCA performed and based on the 22 variables mentioned in Table 2. Factor 1 represents the risk groups; factor 2 the economic conditions; factor 3 the disadvantaged population; factor 4 the level of individual or family income; factor 5 is employment and factor 6 is the dependent population. Each of the six factors will be analyzed in more detail.

\subsubsection{Factor 1 - Aged and dependent groups}

Factor 1 explains $30 \%$ of the model variance, with the dominant variable being the proportion of the population under 5 years old $(+)$ (Table 4). It should be noted that the variable proportion of the population over 65 and the average value of social security pensions are negatively charged (-), thus geographically contrasting with the dominant variable. In the analysis that was made, the variables that compose the present FAC and taking into account the national reality in demographic and social terms - where we verify an aging of the Portuguese population $[28,29]$ and a clear depopulation of the inland areas, mainly in the last five decades -an inversion of the FAC 1 scores (negative cardinality) was performed in the sense that high scores in this factor correspond to high Criticality and vice versa. Thus, it was assumed that municipalities with a high proportion of elderly population and a low average value of pensions tend to have higher Criticality.

The denomination of the FAC as "risk groups" is also explained by the variables describing the proportion of population with difficulties $(+)$, proportion of students by secondary education establishemens $(+)$ and students by pre-school educational establishments $(+)$ that help to characterize groups of most vulnerable population (younger population and population with difficulties). On the other hand, there are two explanatory variables related to housing, namely the proportion of rented accommodation $(+)$ and the proportion of seasonal housing $(+)$. These variables are also theoretically important in the sense that the type of accommodation in which an individual resides reflects, in most cases, their personal, social and economic characteristics $[15,18]$. In this case, it is considered that the greater the proportion of seasonal lodgings, the greater the Criticality, due to the fact that this variable is associated to areas of high tourist interest and to depopulated and aged areas, where dwelling typology houses predominate. FAC 1 is also composed of the average value of social security pensions (-), which allows the identification of individuals with lower average social incomes, allowing one to identify the most weakned and fragil populations.

\subsubsection{Factor 2 - Economic condition}

FAC 2 explains $13 \%$ of the variance, and the variables that contribute to the score are related to the economic condition of the resident population. The dominant variable is the proportion of employees on behalf of others (-), which has a negative score, as opposed to the proportion of self-employed workers as an isolated employer and the proportion of self-employed workers which have positive scores $(+)$. This means that municipalities with high percentages of self-employed and low percentages of employees on behalf of others are more critical in terms of economic status. This is explained by the fact that, in case of a disaster or catasthrophe, the recovery of self-employed persons is more difficult because they have limited access to resources, credit and aid in the post-disaster period. FAC 2 is also constituted by the variables describing the persons employed in the primary sector $(+)$, average value of social security pensions $(-)$ and proportion of seasonal 
Table 4

Criticality components with the corresponding explanatory variables, cardinality and loadings obtained for 2017.

\begin{tabular}{|c|c|c|c|c|}
\hline FAC & Name (\% explained variance) & No of variables & Cardinality & Explanatory variables (loading) \\
\hline 1 & Risk groups (30\%) & 8 & - & $\begin{array}{l}\text { Pop_0_4 (0813), Pop_> } 65 \text { ( }-0809) \text {, Pop_c_dif (0701), Alun_ens_sec (0648), Aloj_arrend (0629), } \\
\text { Alun_pre_esc (0628), Aloj_saz ( }-0583) \text {, Val_med_pens (0561) }\end{array}$ \\
\hline 2 & Economic conditions $(13 \%)$ & 6 & + & $\begin{array}{l}\text { Trab_cont_outr (-0929), Trab_cont_prop_iso (0848), Trab_cont_prop (0799), Aloj_saz (0561), Sec_prim } \\
\text { (0553), Val_med_pens }(-0533) \text {, }\end{array}$ \\
\hline 3 & $\begin{array}{l}\text { Disadvantaged population } \\
(12 \%)\end{array}$ & 4 & + & Ben_rsi (0691), Aloj_r_ < 100 (0668), Ed_ant_1919 (0627), Sec_prim (0529) \\
\hline 4 & Level of income $(7 \%)$ & 2 & - & Dep_clie (0900), Pod_comp (0828) \\
\hline 5 & Employment (6\%) & 2 & - & Sec_ter (0917), Sec_secun $(-0898)$ \\
\hline 6 & Dependent population (5\%) & 1 & + & Aloj_ren_soc $(0843)$ \\
\hline
\end{tabular}

households $(+)$. In this FAC it is considered that the better the economic condition, the greater the capacity to face and recover from catastrophic events.

\subsubsection{Factor 3 - Disadvantaged population}

The beneficiaries of the Social Integration Income (RSI) and Minimum Guaranteed Income (RMG) $(+)$ are the variables with the greatest weight in the present factor, which has a variance of $12 \%$. FAC 3 also includes the proportion of housing units with rental rates below 100 euros $(+)$, proportion of buildings built before $1919(+)$ and proportion of employed population in the primary sector $(+)$. These variables represent the disadvantaged population, considering that the greater the percentage of the beneficiary population of the RSI and RMG, who live in low-rent housing and old buildings and work in the primary sector, the greater the Criticality. This is related to the fact that we are moving, in most cases, towards low-income population, with low socio-professional formation and with a high degree of economic and social dependence on institutional aid, at local, and at the national level.

\subsubsection{Factor 4 - Level of income}

Factor 4 is related to the income level of the population and explains $7 \%$ of the variance. This factor is explained by the following variables: customer deposits in banks, savings banks and mutual agricultural credit $(+)$, which is the dominant variable and purchasing power ratio $(+)$. Both variables are positively charged, however Criticality is greater in proportion to the lower the purchasing power is and the deposits of customers are. Therefore, it was necessary (as previously done in factor 1) to perform an inversion of the FAC scores (negative cardinality) so that low scores in this factor correspond to high Criticality. In this sense, the influence of the level of income and consequent economic capacity are considered as essential factors in the mitigation, resilience and recovery from harmful and catastrophic events.

\subsubsection{Factor 5 - Employment}

Factor 5 is called employment and explains $6 \%$ of the variance of the model. The dominant variable is the proportion of employed population in the tertiary sector $(+)$. This factor is also composed of the variable proportion of population employed in the secondary sector (-). For the present analysis the secondary sector was considered more vulnerable than the tertiary in case of a catastrophic event. Thus, it was necessary to perform an inversion of the values of the variables (negative cardinality) in the sense that high scores in the variable related to the secondary sector correspond to high Criticality. This can be explained by the fact that industrial activities are essentially linked to the private sector (the tertiary sector is mostly associated with the public), with a predominance of small and medium enterprises, where the average salaries and qualifications of their workers are lower than in the tertiary sector. On the other hand, the secondary sector has lower gross value added (VAB) than the tertiary sector, as well as greater exposure to fluctuations in productivity and employment in times of crisis.

\subsubsection{Factor 6 - Dependent population}

Factor 6 explains $5 \%$ of the variance and consists exclusively in the variable proportion of social housing supported by social and supported income (+). Mapping of these FAC scores is relevant for understanding of Criticality since this factor is directly related to the economic power of the population, considering that the smaller this is, the less capacity there will be to prevent, mitigate and recover from disasters or catastrophes.

Fig. 2 shows Criticality index of Social Vulnerability for mainland Portugal at the municipal level for 2008 and 2017. If we analyze the output relative to the Criticality of 2008 we verified that, generically speaking, very low levels are mainly concentrated, along the coastal strip. This is particularly evident in the north and central regions, as well as the Algarve region. The highest values are concentrated in the Douro river valley in the north, the southern border areas of Alto and Baixo Alentejo and in the metropolitan area of Lisbon.

In terms of 2017 Criticality, the lowest values are concentrated in the coastal area, especially in the Algarve region, and in the main regional capitals and their neighboring municipalities. It should be noted that the entire metropolitan area of Lisbon has very low and low Criticality values. Generally, the highest values occur in the north, namely in Alto Tâmega, Trás-os-Montes and the Douro river valley. High Criticality is also found in Central Portugal. Finally, there are also high values of Criticality in most of the municipalities along the border with Spain.

It should be noted that the factors that contribute to the Criticality index vary significantly between regions. Thus, the very low and low values of the metropolitan area of Lisbon are essentially determined by economic conditions and employment, while in the Algarve they are related to employment, and low scores on factors related to risk groups and disadvantaged populations. In terms of the highest values of Criticality, the values of some regions in the north such as Trás-osMontes and Alto Tâmega are fundamentally marked by the economic condition and dependent population, whereas in the Douro river valley the high Criticality is decisively influenced by the economic condition, disadvantaged population and dependent population.

\subsection{Support Capability at municipal level}

The evaluation of the Support Capability allowed us to identify three principal factors (Table 5) that resulted from the PCA carried out based on the 12 variables mentioned in Table 3. Factor 1 represents the response of the civil protection resources; factor 2 the economic and environmental dynamism; and factor 3 the logistics and services capacity. Each of the three factors will be analyzed in more detail below.

\subsubsection{Factor 1 - Civil Protection response}

Factor 1 explains $30 \%$ of the variance of the model, where the dominant variable is the number of firefighter corporations per 1000 inhabitants $(+)$. This factor also includes the variables firefighters per 


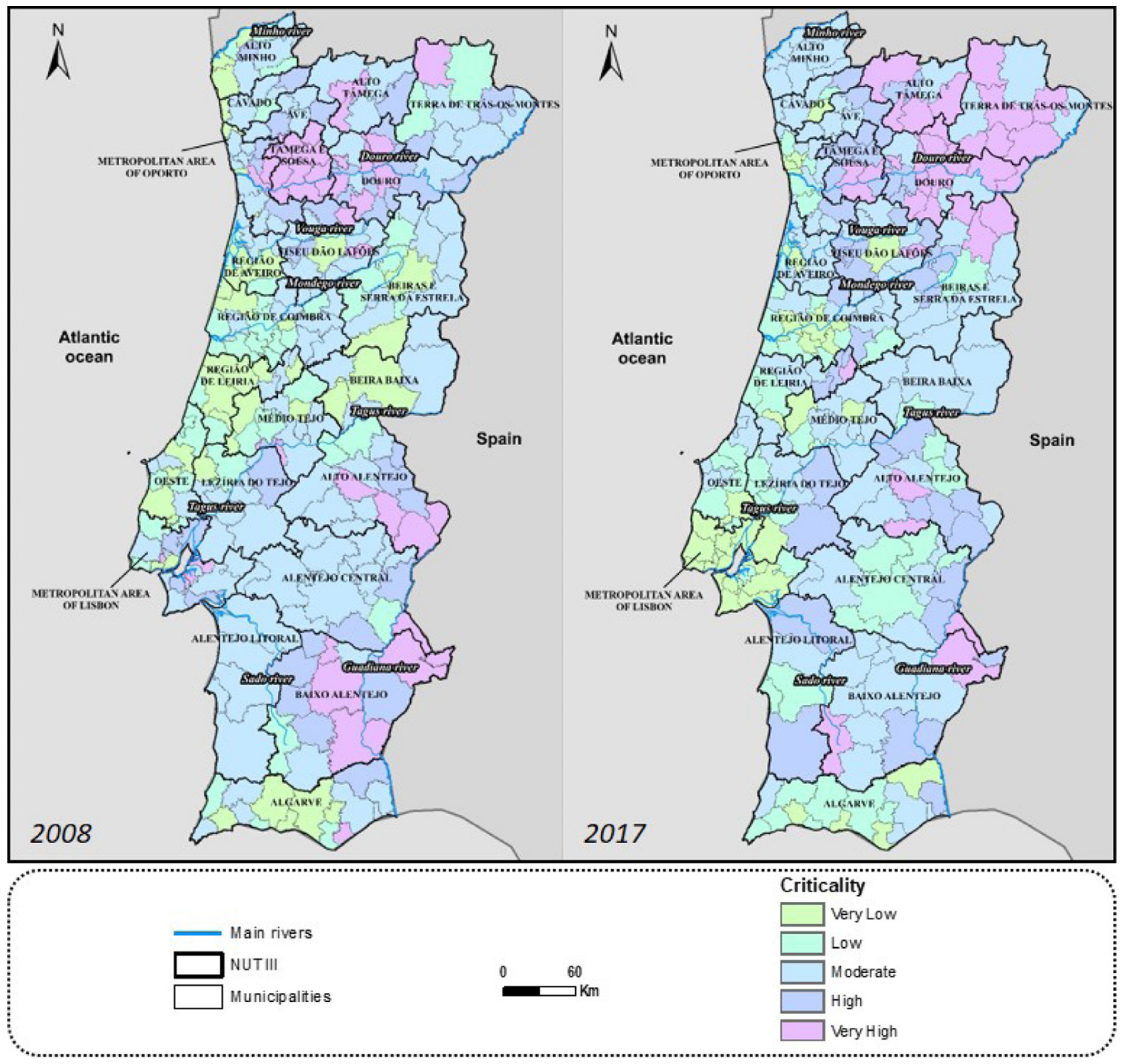

Fig. 2. Criticality in mainland Portugal at the municipal level for 2008 and 2017.

1000 inhabitants $(+)$, average number of inhabitants per covered spaces (-), pharmacies per 10,000 inhabitants $(+)$ and density of road network (-). This factor is an indicator of the municipal Support Capability in civil protection.

\subsubsection{Factor 2 - Economic and environmental dynamism}

This factor represents $22 \%$ of the variance of the model, with the dominant variable being the accommodation capacity in hotel establishments per 1000 inhabitants (+). In addition to this variable, this factor also includes the variable urban waste collected per inhabitant in $\mathrm{Kg}$ /inhab (+), proportion of collective households $(+)$ and ATMs per 1000/inhabitants $(+)$. This FAC expresses a general and broad urban context where the Support Capability, both of public and private nature, assures a faster and more efficient recovery process, while minimizing the impact of functional disruptions.

\subsubsection{Factor 3 - Logistics and services capability}

Factor 3 represents $12 \%$ of the variance, where the dominant variable is the banks and savings banks per 1000 inhabitants $(+)$, followed by the variable ATMs per 1000 inhabitants $(+)$, hospitals per 1000 inhabitants $(+)$ and establishments of insurance agencies per 1000 inhabitants $(+)$. This is also a reflection of economic dynamism and in a disaster scenario the greater the economic dynamism and its logistics and service capacity, the greater the potential for recovery.

Fig. 3 shows the Support Capability index for mainland Portugal at the municipal level for 2008 and 2017. Generically speaking, the analysis of output relate to 2008 Criticality (Fig. 3) allows to verify that the lower values are evident in the north of the country, namely in the NUT

Table 5

Support Capability components with the corresponding explanatory variables, cardinality and loadings obtained for 2017

\begin{tabular}{|c|c|c|c|c|}
\hline FAC & Name (\% explained variance) & $\mathrm{N}^{\circ}$ of variables & Cardinality & Explanatory variables (loading) \\
\hline 1 & Civil protection response $(30 \%)$ & 5 & + & $\begin{array}{l}\text { Corp_Bomb (0909), Bomb_1000 (0873), Hab_esp_cob (-0747), Farm_10000 (0712), Rv_dens } \\
(0.0646),\end{array}$ \\
\hline 2 & $\begin{array}{l}\text { Economic and environmental dynamism } \\
(22 \%)\end{array}$ & 4 & + & Cap_aloj (0888), Res_urb (0833), Aloj_colec_per(0709), MB_1000(0505) \\
\hline 3 & Logistics and services capacity (12\%) & 4 & + & Ban_caix (0708), MB_1000 (0691), Hosp_10000 (0662), Com_segur (0578) \\
\hline
\end{tabular}




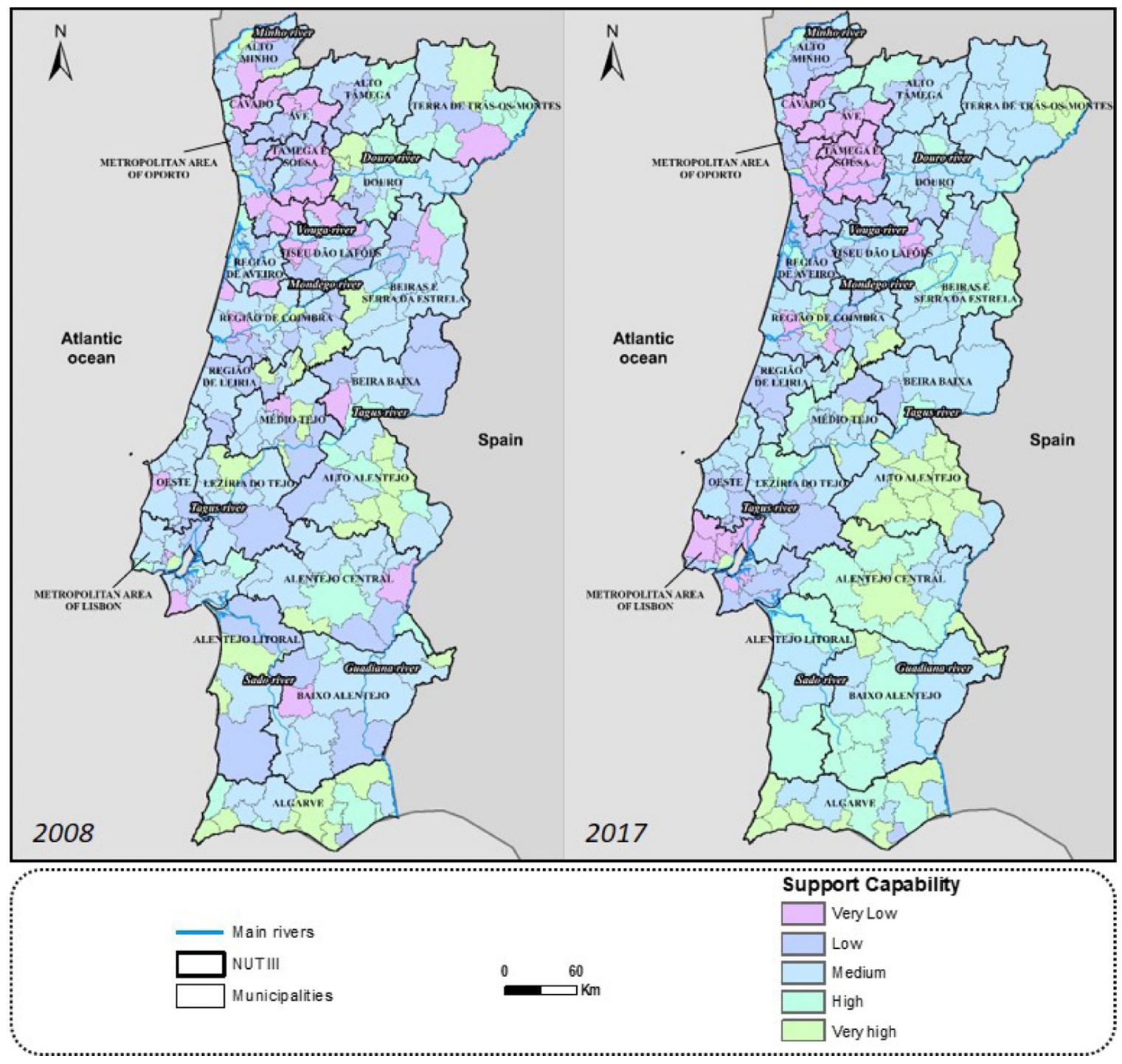

Fig. 3. Support Capability in mainland Portugal at the municipal level for 2008 and 2017.

Cávado, Ave, Tâmega e Sousa and the Oporto metropolitan area. The highest levels are found mainly, in the inland of Portugal, as well as in the Algarve region.

In terms of 2017 Support Capability, according to Fig. 3 the majority of municipalities belonging to the metropolitan areas of Lisbon and Oporto have low and very low levels of Support Capability. They are also highlighted by the low values of Support Capability in the areas of the surrounding municipalities of Oporto, namely in the Alto Minho, Tâmega e Sousa and Cávado and Ave regions. The lower performance of suburban areas around big cities is related to the ratio of the existing equipment and services in relation to the population they are meant to serve.

In most cases the low Support Capability is directly related to municipalities with high population density. On the other hand, the highest values of Support Capability are located mainly in more inland counties, where resources are available for a smaller number of inhabitants, highlighting the Alentejo and the majority of the Algarve municipalities.

\subsection{Social Vulnerability at municipal level}

Fig. 4 shows the Social Vulnerability for mainland Portugal at the municipal level for 2008 and 2017. The combination of Criticality and Support Capability indices using Eq. (1) allowed the calculation of a
Social Vulnerability score for the 278 municipalities of mainland Portugal (Fig. 4) updated for 2017. If we analyze the 2008 output (Fig. 4) we observe that it is worth noting that the very high values are located in the north and northwest areas of mainland Portugal, namely surrounding the Oporto metropolitan area, especially in NUT Tâmega e Sousa and along the Douro river valley. The medium and lowest values are observed in area of Terra de Trás-o-Montes, Beira e Serra da Estrela, Beira Baixa, the litoral area of central region, Oeste and Algarve region.

It should be noted that nowadays the highest values of vulnerability are concentrated in the northern part of the country, namely along the Douro river valley, around the Oporto metropolitan area and the Viseu Dão Lafões region. The very high and high values of Social Vulnerability found in the central and north of the country are largely due to the weak economic power of the resident population and the fragility of its economic fabric. On the other hand, there are also significant percentages of dependent and disadvantaged population in these regions that contribute to aggravate SV, $26 \%$ of the evaluated municipalities present high and very high Social Vulnerability of which, a large majority (92\%), are located in the central and north parts. When analyzing the municipalities with the highest Social Vulnerability Index (SVI), most of them present low and very low scores of Support Capability, namely influenced by factor 2 (economic and environmental dynamism) and factor 3 (logistics and service capacity). On the other hand, all of these municipalities present high and very high values of 


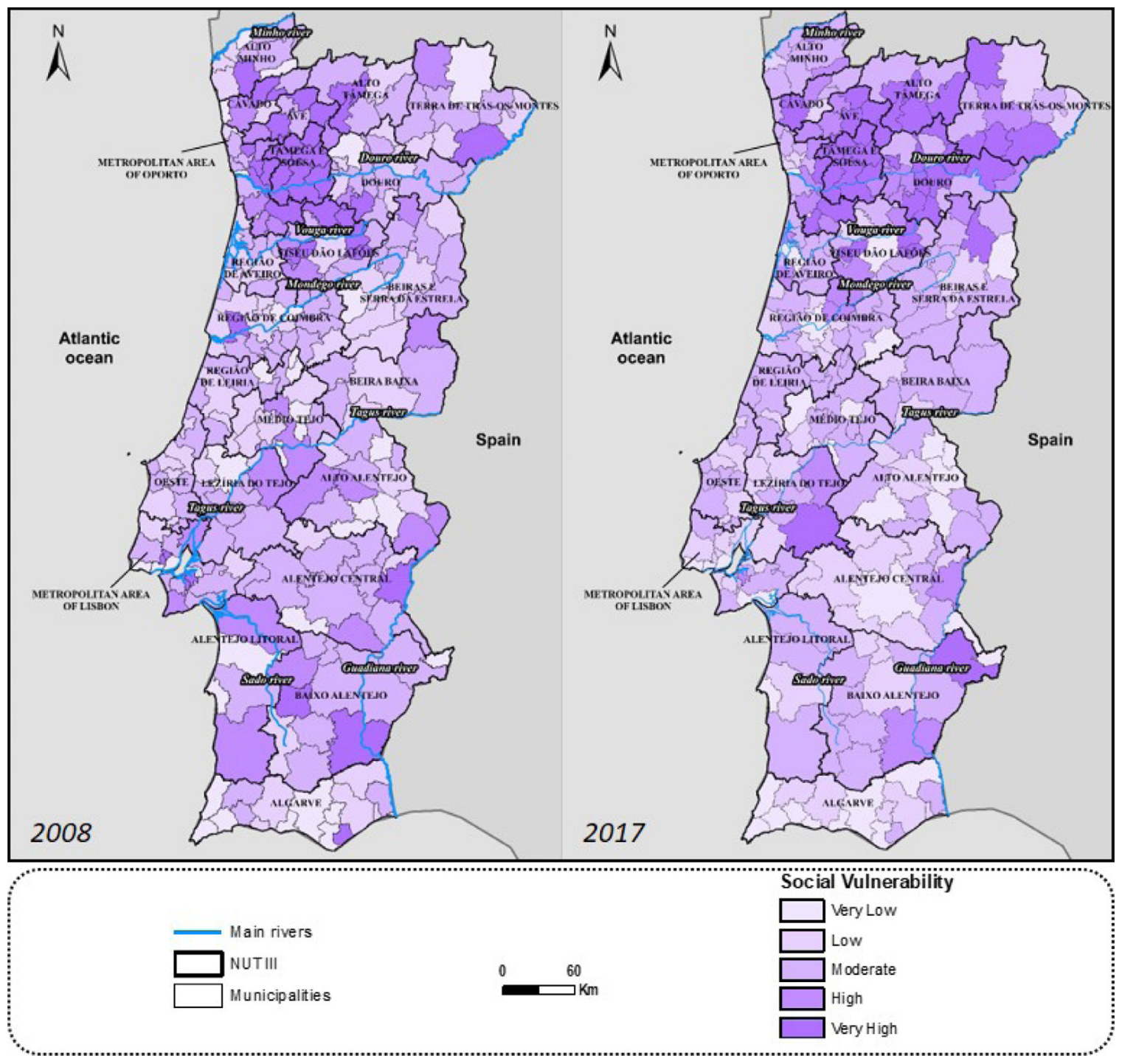

Fig. 4. Social Vulnerability in mainland Portugal at the municipal level for 2008 and 2017.

\section{Criticality}

The 10 municipalities with the lowest values of SV generally present high Support Capacity, and with exception of Oporto, are located in the central and southern parts of the country. The results also show that the SVof all the regional capitals have ranged from very low to moderate. This reveals a territorial concentration of resources and infrastructures in the main cities.

\section{Discussion of results}

With regard to Criticality, it can be seen that in 2017, as in 2008, the municipalities with the highest values are concentrated mainly in the north, especially in the Douro river valley. In terms of Criticality dynamics, there is a general improvement south of the Tagus River, with emphasis on the metropolitan area of Lisbon and in the surrounding municipalities from the Oeste region and Tejo valley. There is also an improvement in the Oporto metropolitan area, with emphasis on the municipalities bordering the regional capital. In spite of the variability and multiplicity of factors that explain the worsening of the Criticality index from municipality to municipality in the period 2008-2017, in general, this is based on factors related to risk groups, the disadvantaged and dependent population (factors 1, 3 and 6), as well as with regard to the economic condition and employment (factors 2 and 5). In terms of Support Capability, it should be noted that all municipalities in the metropolitan areas of Lisbon (with the exception of the municipality of Lisbon and Oeiras) and Oporto (with the exception of the Oporto municipality) have low and very low levels of Support Capability, with a clear deterioration compared to 2008. In general terms, the highest values are concentrated to the north of the Tagus River, a trend already evidenced in the 2008 assessment. In comparison to 2008, there is a clear increase in Support Capability in the southern regions of the Tagus. These improvements are fundamentally associated with variables related to the civil protection response (factor 1) and variables related to the area's economic and environmental dynamism (factor 2). As previously mentioned, the factors that influence Criticality and Support Capability indexes vary from municipality to municipality.

In order to obtain a more detailed and relative understanding of the oscillations that occurred between 2008 and 2017, the score difference was calculated for Criticality (Crit2017 - Crit2008) and Support Capability (SC2017 - SC2008). These calculations gave rise to a Cartesian graph represented in Fig. 5, expressing the evolution of the Criticality and Support Capability in each municipality and respective NUT III in the period between 2008 and 2017.

The analysis of Fig. 5 allows one to conclude that, of the total 278 municipalities, the great majority $(73 \%)$ registered an improvement in Criticality, either alone (33\%) or accompanied by an improvement in Support Capability (40\%). The analysis of each of the four quadrants 


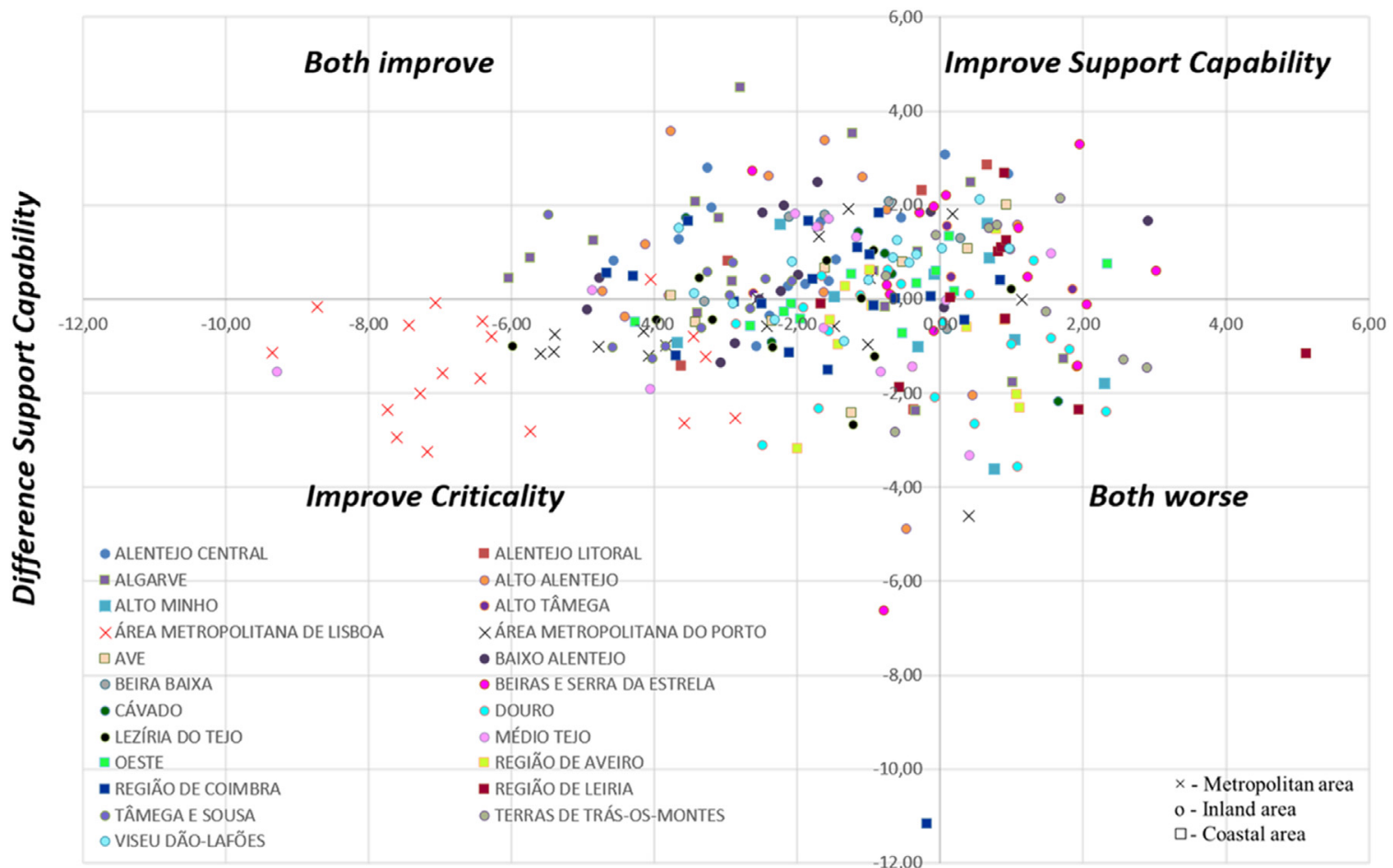

\section{Difference Criticality}

Fig. 5. Criticality and Support Capability evolution between 2008 and 2017 at NUT's III level.

that compose Fig. 5, allows important conclusions. The analysis of the "both improve" (Criticality and Support Capability) quadrant shows that $40 \%$ of the analyzed municipalities are located there, with emphasis on those belonging to the NUT III Viseu Dão Lafões, Alto Alentejo and Algarve. Most of these municipalities are located in the inland area. Regarding the "both worse" quadrant, $12 \%$ of the analyzed municipalities worsened in terms of Criticality and Support Capability, all of which are located in the northern part of the country. In this particular, the municipalities belonging to the NUT's III Douro and Terras de Trásos-Montes stand out as the most representative. Regarding the municipalities that have improved their Support Capability (Improve Support Capability), they represent $15 \%$ of the municipalities analyzed, most of which are located north of the Tagus River.

Finally, the municipalities that registered "Improve Criticality" represent $33 \%$ of the total, highlighting the metropolitan area of Lisbon and NUT's with coastal area.

Regarding the evolution of Social Vulnerability between 2008 and 2017 Fig. 6 shows a graph comparing the value of SV (abscissa) with the difference between the values recorded in 2017 and 2008 (ordinate). The figure shows that the majority (58\%) of municipalities had a reduction in Social Vulnerability values between 2008 and 2017, with $55 \%$ referring to NUT's without coastal areas. Another important fact is that only $4 \%$ of the municipalities analyzed did not have any type of change in terms of vulnerability values.

It should be highlighted that the Tâmega e Sousa region, despite the fact that all the municipalities present Social Vulnerability ranging from high to very high (Fig. 4), was the only NUTIII where all of its municipalities had a decrease of SV from 2008 to 2017. Other regions such as Alentejo Algarve, metropolitan areas of Lisbon and Oporto and Viseu Dão Lafões are NUT's where most of their municipalities presented a reduction in the values of Social Vulnerability. Moving in the opposite direction are the Alto Minho, Beira e Serra da Estrela, Douro, Aveiro and Terras de Trás-os-Montes regions where the majority of their municipalities show an increase in the values of SV.

However, the analysis allows not only for observing differences and variations between regions but also important variations "intra-NUT's", for which purpose the Redundancy Analysis (RDA) software was used (Fig. 7). In this multivariate direct gradient analysis, the variables Diff. SV (difference between Social Vulnerability of 2017 and 2008), Diff. Cr (difference between Criticality of 2017 and 2008) and Diff. SC (difference between Support Capability of 2017 and 2008) were defined as "response variables", whereas the scores of Criticality and Support Capability in both years were defined as the explanatory variables. Three types of analysis can be made from the figure below: a) the position of each NUT III on the abscissa and ordinate axis, the configuration of the arrows (variables) and the relation of the NUT III with the arrows (variables).

The Cartesian axis positions the centroid scores of each NUT (summarizing the respective municipalities' scores) relative to the Criticality difference between 2017 and 2008 (Crit. 2017 - Crit. 2008) and Support Capability difference (SC 2017 - SC 2008). According to Ter Braak \& Šmilauer [26], an acute angle shows a strong positive correlation between the values, meaning in this case that the variation of Social Vulnerability is more related to the variation of Criticality than to Support Capability. According to the same author, the arrow points in the direction of maximum correlation, and the length of the arrow is related to the strength of the correlation. In general, "the longer the arrow, the more highly related that variable is to species composition". We can observe a linear correlation between the abscissa of the figure (Crit.2017 - Crit.2008) and the mean of the Diff. Cr $=0.982929$ (strong positive correlation). In the opposite direction, we can observe a linear correlation between the ordinate of the figure (SC.2017 - SC.2008) and the mean of the Diff. SC $=-0.98557$ (strong negative correlation). If we observe the arrow Diff. $\mathrm{Cr}$, we can verify that the NUT's metropolitan area of Lisbon and Tâmega e Sousa are the ones that had the greatest improvements in average terms between the municipalities that compose the NUT (they point in the opposite direction to the arrow). On the contrary, we find two regions (Terras de Trás-os-Montes and Leiria) as those that showed the greatest aggravation of Criticality (points closest to the Diff. $\mathrm{Cr}$ arrow). Regarding the 


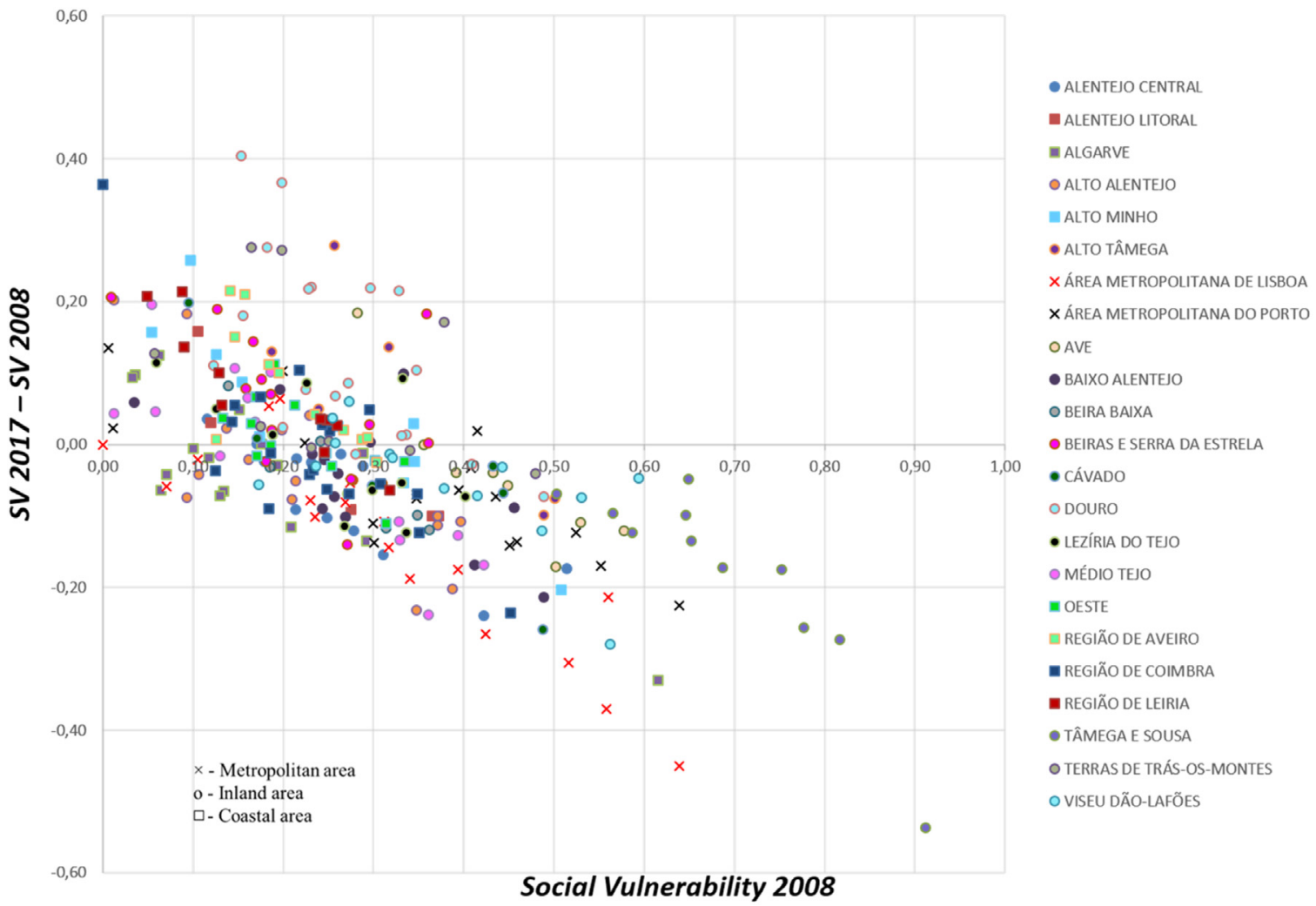

Fig. 6. Social Vulnerability evolutions between 2008 and 2017.

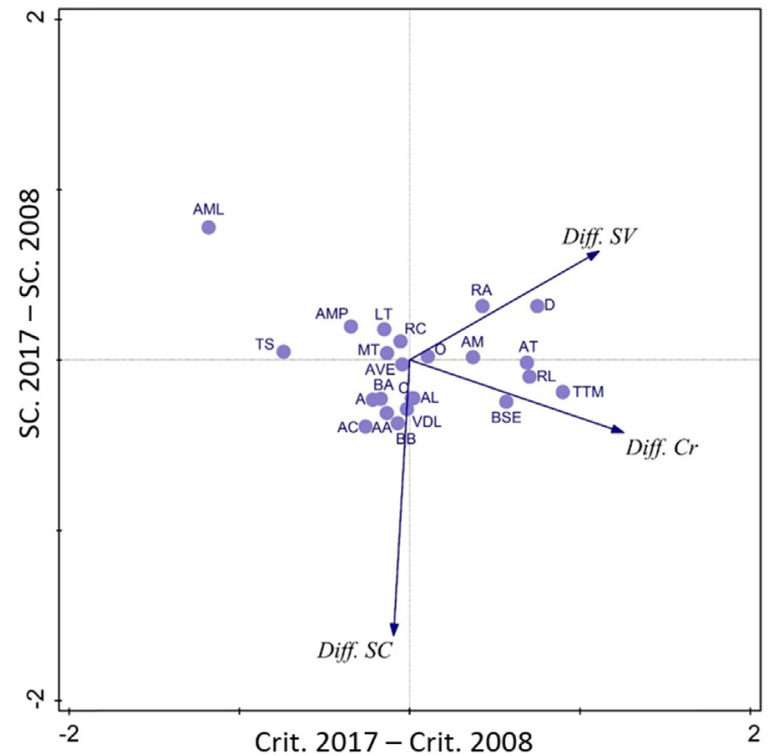

Fig. 7. Diferencers in Social Vulnerability, Criticality and Support Capability in 2017 and 2008 .

Support Capability two inland southtern regions (Alentejo Central and Beira Baixa) showed the largest decreases in SC terms, whereas the Douro region shows the greatest improvements. The multivariate analysis also demonstrates for the composite Social Vulnerability index, contrasted evolution for the Douro and the Terras de Trás-os-Montes regions with the highest increases in SV, related with Tâmega e Sousa and the metropolitan area of Lisbon that, in average terms, have the largest declines in terms of SV. This evaluation allows observation of the general trends of regional evolution in the vulnerability index, not particularizing municipalities. It allows us to realize which variables have most contributed to social vulnerability variation in Portugal, during a decade.

Although the benefits in considering social vulnerability as separated components - criticality and support capability - some general limitations are also found, namely: a) the use of normalized values unables the obtainance of absolute scores of SV that would be compared with results obtained by applying the same method to another study areas; b) for the same reason, the SV scores for a same study area are hardly comparable for different time frames; c) by using a large and diverse type of variables, the method is difficult to be applied to past periods due to potential data unavailability.

\section{Conclusions}

This article presents a comparison between the Social Vulnerability computed for the 278 municipalities of mainland Portugal for two peridos (2008 and 2017) based on the methodology presented in Mendes et al. [18] which is an evolution of the SOVI ${ }^{\circledast}$ methodology [15]. The calculated Social Vulnerability index is based on two dimensions: Support Capability, expressing territorial vulnerability; and Criticality, expressing the vulnerability of individuals and communities. In terms of Criticality, the most relevant factors are related to the economic condition, employment and factors related to the disadvantaged population and risk groups, a finding also noted by Adger [30], Morrow [31] and Fatemi et al. [8]. It is verified that the variation of Support Capability is strongly influenced by the population density, and the factors most relevant to the final results are those related to civil protection response, economic and environmental dynamism and logistic and service capacity. The influence of the territorial resources has also been pointed out as relevant for risk management, namely by Cutter et al. [32] and Fatemi et al. [8].

With regard to Social Vulnerability, the highest values are located mainly in the central and northern part of the country, with emphasis on the region along the Douro river valley and adjacent municipalities. 
The comparison of SV changes between 2008 and 2017 allows identification of some similarities - the highest values are present in northern regions with results aggravation in 2017. On the other hand, there is a general decrease of VS in the southern regions from 2008 to 2017. In spite of the territorial, infrastructural, socio-economic, political and cultural differences existing between the different regions and municipalities analyzed, the model presents results that are consistent, as has already been demonstrated by previous studies [18]. The updating and insertion of new variables in relation to the study carried out in 2008 made it possible to strengthen the model and extend the scope of analysis to realities not previously considered. The comparative cartographic analysis of the values of the two dimensions that compose Social Vulnerability (Criticality and Support Capability) as well as the final values of SV, can be a working tool for different stakeholders, from multiple sectors and authorities at national, regional and local level whose objective is optimized management of resources, as well as in the adoption and application of measures to, mitigation, awareness and prevention.

The multidimensionality that characterizes the present study, resulting from the insertion in the model of a broad set of variables that represent reality in its multiple dimensions, allows the results obtained to be applicable in several dimensions of risk governance. The importance of an enlarged territorial framework is decisive for risk governance as stated on Aven \& Renn [33] and Tavares \& Santos [14].

The resulting characterization from different variables and resulting factors, the cross-referencing of such information with existing regional or local information makes it possible to adjust the public policies and resources to be applied, given the ability to compare regions and municipalities, defining programs that promote capacity and social cohesion, aiming at inequality-reducing policies [34]. This analysis also allows the application of municipal-based risk management strategies at a higher, intra-municipal scale [35].

The intervention and decision-making areas could be the environmental and spatial planning through the use of Social Vulnerability knowledge in the elaboration of urban and spatial planning instruments, where risk management is a central part of the process. On the other hand, in the area of social intervention, where the information resulting from the present study can help to identify the most sensitive areas, by identifying the most dependent and disadvantaged populations, as well as the main risk groups. Also at the level of civil protection, the results of SV and the two dimensions associated with it can assist in the planning and promotion of security strategies and response to crisis, assessing the redistribution of emergency resources adapted in a more realistic way to the multidimensions of risk present. The support capability dimension plays also the role of assessing the existence and coverage of critical infrastructure in disaster risk reduction. Such structure are simultaneously sensitive places of criticality and focal points and networks to the response and recovery. In this regard, the presented research could have deeply considered the role of communication infrastructure. Prevention and risk mitigation must, in fact, account for the population characteristics that might constrain their ability to be informed - for example, illiterate population - and therefore to plan and test alternative forms of communication [36]. A good knowledge of the social vulnerability that exists in a territory will contribute to the construction of more efficient strategies of prevention, mitigation and response to the natural and technological risks, and a better public recognition of risk management models. Despite the limitations presented for the methodology, the results found for the two components show the importance of having a periodic evaluation of social vulnerability. It is important for risk management to understand the trajectories of public policies and their conditioning at the local level. There is thus the possibility of multi-level forms of learning, positively influencing decision-making processes or reducing and mitigating the impact of future hazardous events, as pointed by Voss and Wagner [37].

\section{Acknowledgments}

This work was financed by national funds through FCT - Portuguese Foundation for Science and Technology, I.P., under the framework of the project FORLAND - Hydro-geomorphologic risk in Portugal: driving forces and application for land use planning (PTDC/ATPGEO/1660/ 2014).

\section{References}

[1] J. Birkmann, Measuring vulnerability to promote disaster-resilient societies: conceptual frameworks and definitions, in: J. Birkmann (Ed.), Measuring Vulnerability to Natural Hazards: Towards Disaster Resilient Societies, United Nations University Press, Tokyo, 2006, pp. 9-54.

[2] J. Birkmann, O.D. Cardona, M.L. Carreño, A.H. Barbat, M. Pelling, S. Schneiderbauer, S. Kienberger, M. Keiler, D. Alexander, P. Zeil, T. Welle, Framing vulnerability, risk and societal responses: the MOVE framework, Nat. Hazards 67 (2) (2013) 193-211, https://doi.org/10.1007/s11069-013-0558-5.

[3] S. Fuchs, J. Birkmann, T. Glade, Vulnerability assessment in natural hazard and risk analysis: current approaches and future challenges, Nat. Hazards 64 (3) (2012) 1969-1975.

[4] J.M. Mendes, Sociologia do risco. Uma breve introdução e algumas lições, Territorium 23 (2015) 240-241.

[5] UNISDR, Sendai Framework for Disaster Risk Reduction 2015 - 2030, United Nations Office for Disaster Risk Reduction, Sendai, Japan, 2015.

[6] V. Angeon, S. Bates, Reviewing composite vulnerability and resilience indexes: aa sustainable approach and application, World Dev, 72 (2015) 140-162.

[7] S. Rufat, E. Tate, C.G. Burton, A.S. Maroof, Social vulnerability to floods: review of case studies and implications for measurement, Int. J. Disaster Risk Reduct. 14 (2015) 470-486.

[8] F. Fatemi, A. Ardalan, B. Aguirre, N. Mansouri, I. Mohammadfam, Social vulnerability indicators in disasters: findings from a systematic review, Int. J. Disaster Risk Reduct. 22 (2017) 219-227.

[9] B. Wisner, P. Blaikie, T. Cannon, I. Davis, At Risk: Natural Hazards, People's Vulnerability and Disasters, 2nd ed., 471 Routledge, 2004.

[10] S. Tapsell, S. McCarthy, H. Faulkner, M. Alexander, Social vulnerability and natural hazards. CapHaz-Net WP4 Report, Flood Hazard Research Centre-FHRC, Middlesex University, London, 2010.

[11] W. Chen, S. Susan, C. Emrich, P. Shi, Measuring social vulnerability to natural hazards in the Yangtze river delta region, China. International, J. Disaster Risk Sci. 4 (2013) 169-181.

[12] E.E. Koks, B. Jongman, T.G. Husby, W.J.W. Botzen, Combining hazard, exposure and social vulnerability to provide lessons for flood risk management, Environ. Sci. Policy 47 (2015) 42-52.

[13] J.L. Barros, A.O. Tavares, A. Santos, A. Fonte, Territorial vulnerability assessment supporting risk managing coastal areas due to tsunami impact, Water 7 (2015) 4971-4998.

[14] A.O. Tavares, P.P. Santos, Re-scaling risk governance using local appraisal and community involvement, J. Risk Res. 17 (7) (2014) 923-949, https://doi.org/10. 1080/13669877.2013.822915.

[15] S.L. Cutter, B.J. Boruff, W.L. Shirley, Social vulnerability to environmental hazards, Social. Sci. O. 84 (2) (2003) 242-261.

[16] Y. Ge, W. Dou, N. Liu, Planning resilient and sustainable cities: identifying and targeting social vulnerability to climate change, Sustainability 9 (8) (2017) 1394.

[17] J.M. Mendes, Social vulnerability indexes as planning tools: beyond the preparedness paradigma, J. Risk Res. 12 (2009) 43-58.

[18] J.M. Mendes, A.O. Tavares, L. Cunha, S. Freiria, A vulnerabilidade social aos perigos naturais e tecnológicos em Portugal, Rev. Crítica De. Ciências Sociais 93 (2011) 95-128.

[19] A. Lauge, J. Hernantes, J.M. Sarriegi, Critical infrastructure dependencies: a hol istic, dynamic and quantitative approach, Int. J. Crit. Infrastruct. Prot. 8 (2015) (2015) 16-23, https://doi.org/10.1016/j.ijcip.2014.12.004.

[20] I.N.E. Censos, Resultados Definitivos e Portugal 2012 National Institute of Statistics, Lisbon, 2011.

[21] M. Schmidtlein, R. Deutsch, W. Piegorsch, S. Cutter, A sensitivity analysis of the social vulnerability index, Risk Anal. 28 (2008) 1099-1114.

[22] C. Guillard-Gonçalves, S.L. Cutter, C.T. Emrich, J.L. Zêzere, Application of social vulnerability index (SoVI) and delineation of natural risk zones in Greater Lisbon, Portugal, J. Risk Res. 18 (5) (2015) 651-674.

[23] B.M. de Loyola Hummell, S.L. Cutter, C.T. Emrich, Social vulnerability to natural hazards in Brazil, Int. J. Disaster Risk Sci. 7 (2) (2016) 111-122.

[24] A.O. Tavares, J.L. Barros, A. Santos, Multidimensional approach for tsunami vulnerability assessment: framing the territorial impacts in two municipalities in Portugal, Risk Anal. 37 (4) (2017) 788-811, https://doi.org/10.1111/risa.12678.

[25] PORDATA. Base de dados Portugal Comtemporâneo. 〈http://pordata.pt/〉, 2017 (Accessed August 2017).

[26] C.J.F. Ter Braak, P. Šmilauer, CANOCO reference manual and user's guide: software for ordination (version 5.0). Biometris, 2012.

[27] A. Comrey, H. Lee, A First Course in Factor analysis, Physiology Press, New York, 2009.

[28] M.J.V. Rosa, O envelhecimento da sociedade portuguesa, ed. Fundação Francisco Manuel dos Santos, Lisboa, 2016.

[29] INE. Projeções da população residente 2015-2080, National Intitute of Statistics. 
Lisbon, 2017:〈https://www.ine.pt/xportal/xmain?Xpid = INE\&xpgid = ine_ destaques\&DESTAQUESdest_boui $=277695619 \& D E S T A Q U E S m o d o=2 \&$ xlang $=\mathrm{pt}\rangle$.

[30] W.N. Adger, Social vulnerability to climate change and extremes in coastal Vietnam, World Dev. 27 (1999) 249-269.

[31] B.H. Morrow, Identifying and mapping community vulnerability, Disasters 23 (1999) 1-18.

[32] S.L. Cutter, J. Mitchell, M. Scott, Revealing the vulnerability of people and places: a case study of Georgetown county, South Carolina, Ann. Assoc. Am. Geogr. 90 (2000) 713-737.

[33] T. Aven, O. Renn, Risk management and governance, Concepts, Guidelines and Applications, Springer-Verlag, Berlin, 2010
[34] T.G. Measham, B.L. Preston, T.F. Smith, C. Brooke, R. Gorddard, G. Withycombe, C. Morrison, Adapting to climate change through local municipal planning: barriers and challenges, Mitig. Adapt. Strateg. Glob. Change 16 (8) (2011) 889-909.

[35] A., A. Agrawal, M. Kononen, N. Perrin, The Role of Local Institutions in Adaptation to Climate Change. Social Development Working Papers, The World Bank, Washington DC, 2009 (Available at: 〈http://siteresources.worldbank.org/ extsocialdevelopment/Resources/244362 -1164107274725/sdp118.pdf $\rangle$.

[36] E.Y. Sanchez, S. Represa, D. Mellado, K.B. Balbi, A.D. Acquesta, J.C. Lerner, A.A. Porta, Risk analysis of technological hazards: simulation of scenarios and application of a local vulnerability index, J. Hazard. Mater. 352 (2018) 101-110.

[37] M. Voss, K. Wagner, Learning from (small) disasters, Nat. Hazards 55 (3) (2010) 657-669. 